\title{
DISCUSSION ON THE TREATMENT OF CONGENITAL SYPHILIS *
}

\author{
By DAVID NABARRO, M.D., F.R.C.P.
}

LAdies AND GentLEMEn,-As I am responsible for having suggested to the Council of our Society the subject for discussion this evening, I should, perhaps, give you my reasons for so doing. During the past seventeen years, from the very inception of the V.D. Clinic system, I have been in charge of the clinic at the Hospital for Sick Children, Great Ormond Street, and have personally carried out or supervised the treatment of nearly all the cases of congenital syphilis admitted to the hospital. As new drugs have been put on the market many different courses of treatment have been adopted, and as the patients are of all ages, and the symptoms vary in different cases, e.g., rash and snuffles, periostitis, neuro-syphilis with hemiplegia or mental symptoms, interstitial keratitis, hæmoglobinuria, and so forth, it is almost impossible for one individual to gather experience of a sufficiently large number of each type of case treated by the many different drugs available. It is, of course, quite likely, indeed practically certain, that congenital syphilis can be cured by several different methods of treatment, nevertheless, in my opinion, a useful purpose will be served if we take stock of the experience which has been gained by workers in this country in the treatment of this disease. In order to facilitate the discussion, and to draw the attention of the members to particular points upon which I think information is desired, I have drawn up a series of questions which I think you have all seen. Some work has been done in this country and in America, and probably, too, in other countries, upon the results of treatment of acquired syphilis in the adult. Thus, the M.R.C. published in I929 a report by Colonel Harrison on the treatment of syphilis based on the records from St. Thomas's Hospital.

* Held at a meeting of the Medical Society for the Study of Venereal Diseases on November $24^{\text {th, }}$ I 933 . 


\section{BRITISH JOURNAL OF VENEREAL DISEASES}

In America, Moore and Kemp, of Johns Hopkins Hospital, published a series of reports in 1926, and in 1932-3 the periodical Venereal Diseases Information, issued by the U.S. Public Health Service, published a "Series of Co-operative Clinical Studies" in the treatment of syphilis, based on the records of five American clinics. So far as I am aware, there has been no similar considerable volume of experience collected of the treatment of congenital syphilis, and .I hope that the outcome of this discussion may be that certain general principles as regards drugs, dosage, mode of administration, duration of treatment, and so forth, may be arrived at.

The first point to emphasise, though of course it is well known and generally recognised by syphilologists, is that by the treatment of a syphilitic mother during pregnancy, congenital disease in the child can be almost certainly prevented. Unfortunately, this fact is far too little realised and acted on by the general body of the profession, and I have even known cases where a syphilitic mother has passed undiscovered through the net of an ante-natal clinic.

The next point in connection with congenital syphilis is this : the earlier in life the patient is treated, the more likely is one to achieve success in the eradication of the disease. A point of importance is that the treatment to be effective as speedily as possible must be carried out systematically and with regularity. As to how long treatment should be continued, probably we shall find that there will be considerable difference of opinion. The same remark will apply to the choice of drugs to be used, and I think I cannot do better, after these few preliminary remarks, than continue my observations along the lines indicated by the series of questions referred to above.

First, with regard to the use of mercury, I think I may take it for granted that the majority, if not all of you in this room to-night, would hesitate to rely on mercury alone in treating a child with congenital syphilis. There are, however, some members of the older school of thought who still believe that mercury is adequate in the treatment of congenital syphilis, and who still persist in using it in the time-honoured manner, namely by giving hyd. cum cret. and inunctions of mercury. It is quite possible that cases may be cured in this way, and 


\section{TREATMENT OF CONGENITAL SYPHILIS}

there is no doubt that the symptoms, and particularly the rash and snuffles of early infancy, quickly disappear under this treatment, but I very much doubt if many cases are really cured by it, so that their serological tests are negative, and later manifestations of the disease prevented. I can recall one case that was apparently adequately treated with mercury in infancy and for nine years afterwards, yet at the end of that time had a strongly positive W.R. and was by no means a healthy specimen physically and mentally. I have seen other cases in which mercury had been given over a number of years, but perhaps somewhat irregularly, and the children had not been cured of their disease. In my own practice I frequently give infants mercurial treatment for the first week or two, before beginning the arsenic injections, because I think it is milder in its action than arsenic and perhaps bismuth; also I nearly always give mercury in conjunction with arsenic injections, and have now for many years used almost entirely the green iodide of mercury, gr. $\frac{1}{8}$ to $\frac{1}{4}$, two or three times a day. Mercury is still used by some practitioners, even for older children suffering from syphilitic periostitis and hemiplegia.

Coming now to my second main heading - "Do you rely on arsenicals ?" I think most, if not all, of you will probably say " Yes," with possibly some reservation or other. There is no doubt that the discovery of salvarsan by Ehrlich introduced a new era into the treatment of syphilis. It is unnecessary for me to dilate upon this point, or to spend much time over the different drugs which have been and are employed for the purpose.

In the earliest days we had only " 606 ," salvarsan or arsphenamine and "9I4," neo-salvarsan or neo-arsphenamine, both of which were intended for intravenous administration. In treating children, intravenous injection may be quite a simple matter in those over the age of three or four years, but below that age it may be difficult, if not impossible, to inject the arm veins, and I used then to inject the drug into the external jugular vein and scalp veins. I was not particularly keen on making the injections into the scalp veins, as these are often so freely movable that there is a danger of the needle either going right through them or slipping out, thus giving rise to a hæmatoma or leaking of the drug 


\section{BRITISH JOURNAL OF VENEREAL DISEASES}

around the vein. At that time there was no special needle invented for injections into the longitudinal sinus, and I considered it unsafe, as indeed I still do, to give injections by that route, although it might be perfectly safe to withdraw blood through the anterior fontanelle for a test. Consequently, one thought of giving the "9I4" intramuscularly. At first this was done by adding creocamph or stovaine, but later the drug was dissolved in water in the ordinary way, and injected into the muscles without the child apparently suffering much pain. This mode of injection of " $9 \mathrm{I} 4$ " is now ancient history, and no longer necessary, because we have the sulphur-containing preparations (sulfarsenol, sulphostab, neo-kharsulphan, sulpharsphenamine, etc.) which have been specially introduced for subcutaneous or intramuscular injections, and these are now largely used in the treatment of children. These injections are generally painless, but occasionally one comes across a patient in whom they are unusually painful, and I find that by using a special solvent, containing chlorbutol gr. $\frac{1}{26}$, ethocain $\mathrm{HCl}$ gr. $\frac{1}{4}$, glucose 55 per cent. I c.c., the pain associated with the injection is obviated.

As regards dosage, for several years I have started infants at $\mathrm{I} \frac{1}{2}$ or $2 \mathrm{cgm}$. of sulfarsenol, and increased by easy stages up to a maximum of 6 to $8 \mathrm{cgm}$. at the end of the first course of eight injections. On one occasion, by mistake, the second dose given was not $2 \mathrm{cgm}$. but I2 cgm., and as the infant showed no ill effects from this dose, I continued with this dose for the remainder of the first course, to the child's obvious advantage, for the W.R. was almost negative at the end of the course. Since that time I have been in the habit of giving considerably bigger doses than I had previously done, and I am showing you the treatment record of a child I have still under treatment, who is now undergoing the sixth series of injections, and has had more than $9 \mathrm{gm}$. of sulfarsenol at the age of one and seven-twelfths, doses of $30 \mathrm{cgm}$. sulfarsenol being those now usually given to her. One should perhaps mention that some German authorities recommend giving quite big doses to infants, such as 0.03 or $0.04 \mathrm{gm}$. per kilogram of body weight, which would be $0 \cdot 12$ to $0 \cdot 16 \mathrm{gm}$. for an infant weighing 8 or $9 \mathrm{lb}$. I have not myself been in the habit of weighing infants before injection, but have generally been guidec 


\section{TREATMENT OF CONGENITAL SYPHILIS}

by the size, general condition, and age of the child, and I should be interested to know if many of you weigh your patients in order to calculate the amount of a drug which should be given. For older children the starting doses would be bigger - 6 to I 2 cgm., and the maximal dose might be 36 or even 42 cgm., at twelve years of age.

The drugs I have used intravenously have been novarsenobillon (N.A.B.), neo-kharsivan, Bayer's neosalvarsan, Boots's stabilarsan and neo-silver-salvarsan, but for one reason or another several of these preparations have been discarded, and to-day one uses mainly N.A.B. (novarsenobillon) for intravenous injections. The initial doses are usually $\mathrm{O} \cdot \mathrm{I}$ or $\mathrm{O} \cdot \mathrm{I} 5 \mathrm{gm}$., and the maximum $0.45 \mathrm{gm}$. for children up to twelve. For many years I gave six injections at weekly intervals, with a month's rest between courses, but lately I have been giving eight injections in a course. Forty or fifty injections totalling perhaps I2 to $\mathrm{I} 4 \mathrm{gm}$. of the drug have been given in some cases. I nearly always supplement arsenical treatment with mercury iodide pills, occasionally by inunctions of mercury ointment, or by injections of bismuth. I have not found that any particular preparation of arsenic is to be preferred to any other in special types of case, with the exception perhaps of tryparsamide and neo-silver-salvarsan in neuro-syphilis, about which I shall speak later on.

Should the treatment be continuous or intermittent? I think most authorities are agreed that it is desirable to give patients a rest from active treatment at regular intervals, during which time the body is able to eliminate these toxic substances, and at the same time give tonics such as cod-liver oil and malt, etc., to help to restore the resisting power of the tissues. The American observers above referred to state that in early syphilis continuous treatment is definitely superior to intermittent treatment, but in latent syphilis apparently this is found not to be the case, and I am not aware that continuous treatment of congenital syphilis has been recommended.

As regards the other drugs given with arsenicals, I think I have already mentioned that in the majority of cases mercury is given by mouth, because one is always desirous of avoiding pricking one's small patients too much, as would be required if one gave injections of mercury or bismuth, in addition to the arsenical prepara- 


\section{BRITISH JOURNAL OF VENEREAL DISEASES}

tion. There are other arsenical preparations, such as acetylarsan, which I have not mentioned, because I have no personal experience of their use.

We come now to the administration of arsenical preparations by mouth. For some years the drug "spirocid" (otherwise stovarsol, orarsan) has been used for the treatment of congenital syphilis in Germany, and it is so highly thought of, that I am told by several German syphilologists that injection treatment of congenital syphilis has been almost entirely given up in many German clinics. At a congress held in Geneva in I932, several German participants claimed to have cured cases of congenital syphilis with stovarsol, but I think the evidence they brought forward is not conclusive, because obviously sufficient time has not been allowed to elapse in order that one can be certain that there would be no serological or clinical relapses. I have a number of children just now who are being treated with " orarsan" by mouth, but I consider it will be several years before one can be in a position to say that these children have been cured. One great and obvious drawback to this form of treatment is that, certainly amongst the hospital class of patient, one can rarely be certain that the drug is being given as one intends it to be, whereas by injection, one knows definitely how much of a drug the patient receives on each occasion.

As regards the mode of administration of stovarsol or orarsan, the present scheme which I adopt is one which was outlined to me by Professor Hamburger of Vienna. His assistant, Dr. Alois Bratusch-Marrain, wrote a paper in I930 upon the treatment of congenital syphilis with spirocid, and he came to the conclusion that it was of very great value in curing the disease and in preventing relapses. The scheme of dosage recommended is as follows :-

Daily dose in the first week $0.005 \mathrm{gm} .=\frac{1}{12} \mathrm{gr}$. per $\mathrm{kgm}$. body weight.

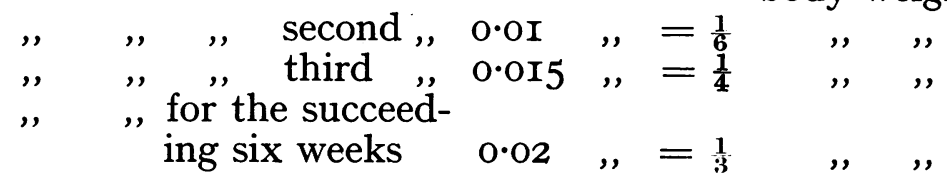

After this course of nine weeks' treatment, a rest of four to six weeks is given, and the course is repeated

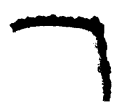




\section{TREATMENT OF CONGENITAL SYPHILIS}

once or twice if necessary. The author states that doses in excess of those recommended produce no additional beneficial effects upon the patient. As I have already mentioned, I think oral treatment of congenital syphilis is, or may be, somewhat uncertain if one cannot rely upon the mother, or whoever may be looking after the child, but if it can be given in an institution where the children are under skilled supervision, it should certainly be given a trial. I am treating a number of infants with it at St. Margaret's Hospital, where the children are in residence for six months, or even longer, but although several of them have become serologically negative, it is too early to say definitely whether they are actually cured. If it should turn out eventually that stovarsol can cure congenital syphilis, this will be a very distinct advance over treatment by injections.

The next heading in relation to the treatment of congenital syphilis is treatment by bismuth. It is shown experimentally that bismuth is not nearly so powerful a spirochæticide as arsenic, yet one has found clinically that it does clear up lesions of florid congenital syphilis very rapidly, and, moreover, that it can also render the blood sero-negative. I have treated quite a number of children with bismuth alone, and I am following up as many of these cases over as many years as possible, in order to ascertain whether they are permanently cured clinically and serologically. It will be interesting to hear if others have made observations on similar lines, because if it could be ultimately shown that bismuth is almost, if not quite, as valuable as arsenic in the treatment of syphilis, this will make a very marked difference in the cost of running V.D. clinics. There are many bismuth preparations upon the market, water soluble, insoluble and lipo-soluble. Then there are compounds, containing arsenic and bismuth in combination. I have tried a number of these preparations, trépol, neo-trépol, metallic bismuth, muthanol, but for the last few years I have used solely bismuth oxy-chloride, or bisoxyl. It has been stated that bismuth is particularly of value in the treatment of interstitial keratitis. I cannot say that my experience bears this out, because I have had extremely good results with arsenic and mercury iodide, and I do not think I have found bismuth to be preferred to arsenic in any particular type of case. The dose to be injected 


\section{BRITISH JOURNAL OF VENEREAL DISEASES}

will of course depend upon the weight of the patient, and the proportion of metal in the preparation used. Bisoxyl contains $\mathrm{O} \cdot \mathrm{I} \mathrm{gm}$. of bismuth oxy-chloride $=$ $0.08 \mathrm{gm}$. metallic bismuth, and $0.005 \mathrm{gm}$. of chloretone in each cubic centimetre. My usual starting dose for an infant of say 4 kilos. weight is $0 \cdot I$ c.c. bisoxyl, increasing by $0 \cdot I$ or $0 \cdot 2$ c.c. each week up to a maximum of I c.c. for the ninth or tenth injection in the first course. Such a course rapidly clears up the lesions, and also may make the W.R. negative. It is important to examine the urine frequently, because bismuth does undoubtedly affect the kidneys during its excretion, and one very frequently finds a trace of albumen, and possibly a certain number of casts in the urine.* Mercury is not given when treatment by bismuth is undertaken. I have myself not used the preparations "bivatol" or " biliposol," which consist of oily solutions of bismuth salts, the former being according to the recent letter contributed by Dr. Marshall Findlay to the British Journal of Venereal Diseases, basic bismuth a-carbethoxy$\beta$-methylnonoate, the latter a solution of camphocarbonate of bismuth in ether-purified olive oil. $\dagger$ Findlay suggests that the use of oily solutions of bismuth salts tends to avoid the possible toxic effects of the watersoluble salts on the one hand, and the formation of depôts of metal or insoluble salts on the other. I should like to hear the experiences of those of you who may have used either of these preparations in the treatment of congenital syphilis.

With regard to the use of iodides in congenital syphilis, I personally very seldom give the iodides of potassium or sodium to children, but as I have already indicated, practically all the mercury which I give to my patients is in the form of the green iodide. I have treated, and I think with benefit, one or two cases of juvenile tabes dorsalis with intravenous injections of sodium iodide.

With regard to the use of adjuvants, I think we shall all agree that in the treatment of congenital syphilis, and

* I have recently been treating an infant who at eight weeks weighed $94 \mathrm{lb}$. and was given nine weekly injections of "bisoxyl" - total 5.8 c.c. Four weeks later the W. R. and Kahn, which had been strongly positive, were negative. At twenty-one weeks (weight $I_{4} \frac{1}{2} \mathrm{lb}$.) he started another course and was given seven injections bisoxyl, totalling 5.3 c.c. : W.R. and Kahn again negative; at ten months, weight $26 \mathrm{lb}$., he was given a course of r-c.c. injections weekly. EDs.

$\dagger$ See a second letter from Dr. Marshall Findlay on page 66 of this number.- 


\section{TREATMENT OF CONGENITAL SYPHILIS}

particularly in the case of infants, the general treatment of the patient must not be neglected. If still on the breast the infant should be kept there as long as possible, always bearing in mind the fact that it is obtaining additional drug, probably arsenic, if the mother herself is having injections. If the child is not being breast fed, then the most suitable substitute must be found, and details of general hygiene such as fresh air and sunshine, and suitable clothing must be attended to, and vitamins A and D supplied in the form of cod-liver oil and malt, radiostoleum, adexolin, etc. For marked anæmia, iron may be necessary, and during the intervals between the injections general tonics, such as syr. ferri. phos. or codliver oil and malt should be given.

The next heading I will consider is neuro-syphilis. In my experience this is an important aspect of congenital syphilis, and too big a subject for me to consider at any length this evening. By the routine examination of the cerebro-spinal fluid in cases of congenital syphilis, one discovers a considerable number of children with positive evidence of C.N. system syphilis. In the case of infants and very young children one treats such cases more intensively than those in which the spinal fluid is not involved, and with the usual drugs, arsenic and mercury or arsenic and bismuth, and by impressing upon the mother the extreme importance of regular attendance in these cases, one generally succeeds in having the child brought for treatment as often as is necessary, and as a rule the spinal fluid clears up as a result of this line of treatment. Sometimes, however, serious nervous lesions are manifested, particularly hemiplegia, in children perhaps three or more years old, and in these cases one has been in the habit of using tryparsamide, which has been so strongly recommended for neuro-syphilis by David Lees. A course of eight or ten injections of tryparsamide, starting at $0.5 \mathrm{gm}$. and working up to $2 \mathrm{gm}$., is given, and in some cases injections of bisoxyl have been given intramuscularly with the tryparsamide. The courses of injections may have to be repeated several times, and even so, the blood and c.s.f. may not become normal. In such cases I have tried giving malaria followed by further courses of injections, and in some of the cases one has succeeded in getting the blood and fluid eventually Wassermann negative. I always endeavour 


\section{BRITISH JOURNAL OF VENEREAL DISEASES}

to render the c.s.f. normal if I can before ceasing to treat the patient, because I think the outlook is distinctly bad if an active cerebro-spinal syphilis is allowed to persist. I should be interested to hear if any member has noted that neuro-syphilis has supervened in a patient who has had inadequate early treatment, either with mercury, bismuth or arsenic, because it has been alleged, perhaps with a certain amount of truth, that inadequate treatment of early syphilis in adults leads to subsequent neuro-syphilis.

I should like to make a few remarks about interstitial keratitis, which is in my experience one of the commonest, if not the commonest manifestation of late congenital syphilis, and also one of the most difficult to guard against. Some ophthalmologists, especially those of the older school of thought, will not treat I.K. with injections, because they say that it does no good to the eye condition. I do not agree with that statement, and even if it were true, I.K. is only one manifestation of the child's disease, and it is the disease which needs treatment. In my experience treatment by injections, either of arsenic or bismuth, very rapidly clears up the condition of the eyes, and in quite a number of cases one has succeeded in preventing the second eye from becoming affected; on the other hand, one must admit that one has seen I.K., of a mild form, it is true, arising in a child who was undergoing treatment by injections and whose W.R. was negative; nay, more, I have seen it arise in a child who for eight years had had a negative W.R., and whom one could have legitimately regarded as cured of her disease. I have had a few other cases of I.K. arising some time after the W.R. had become negative, and curiously enough, all of these cases I believe had been originally treated with bismuth alone. If further experience confirms this observation, it would follow that bismuth treatment alone is not a safe and certain cure for congenital syphilis. Possibly the experience of some of you here present this evening may help to answer the question whether interstitial keratitis (either an original attack or relapses) is more likely to occur after one form of treatment than another.

\section{Toxic Manifestations}

On the whole, children are very tolerant of the various drugs which are used in the treatment of congenital 


\section{TREATMENT OF CONGENITAL SYPHILIS}

syphilis. I need hardly spend much time in speaking of the toxic effects of mercury, which are well-known to all of you. With regard to arsenic, the toxic symptoms may occur soon after the injection is given: the so-called " nitritoid " crises, in which there may be swelling and duskiness of the face and limbs, perhaps associated with nausea or vomiting and diarrhœa. The more severe manifestations, such as dermatitis, jaundice and encephalitis, are very rarely seen in children. I have myself had one fatal case of dermatitis after N.A.B., and one of encephalitis, but no fatal case of jaundice, though a few patients have shown this symptom in a mild degree. Sodium thiosulphate injections have proved useful in the treatment of these toxic manifestations, but I have never had occasion to dissolve the N.A.B. in thiosulphate, as has been recommended by some authorities. I personally have not been in the habit of preparing my patients in any way for their injections ; for example, by giving glucose, and I shall be interested to hear if any of you have adopted this practice in your clinics.

With regard to bismuth, this drug is usually said to be, and no doubt is, less toxic in its effects than are the arseno-benzene compounds, but as a result of the rather large doses of bisoxyl which I have been giving of late, several of my patients have developed a blue line in the gums, and in one or two of them a somewhat severe gingivitis. Several of the children have shown some affection of the kidneys, and it is important when injecting bismuth to examine the urine very frequently. Albumen or casts or both may be present in the urine, and when they are found, one either misses an injection, or perhaps suspends the treatment for a month. In my experience the condition clears up entirely, for I have not seen any permanent condition of nephritis resulting from bismuth treatment.

Next we must consider the duration of treatment and criteria of cure, and it is probably in this section that we shall find the most diversity of opinion amongst the authorities. The first principle by which I am guided in this respect is to give the child the minimum of treatment which is necessary to effect a cure, because there is no doubt that the majority of children dislike the injections, and indeed with some of them the weekly visit to the hospital is almost a nightmare. It is in such cases

$$
r^{\text {y. }}
$$




\section{BRITISH JOURNAL OF VENEREAL DISEASES}

that I have recently resorted to the administration of orarsan by mouth.

For many years it was my practice to go on giving courses of eight intramuscular injections, together with mercury iodide pills, until the W.R. became quite negative, and to give one further course afterwards. The child was then seen, and the blood tested, every three months during the first year, twice or three times during the following year, twice the year after, and subsequently every year, if possible, until puberty or even later. Acting on this principle, I sometimes found it necessary to give only two courses of injections, and the children have apparently remained now for several years free from signs or symptoms of the disease. Whether they are really cured by this comparatively small amount of treatment one will only be able to tell with certainty as the years roll by. There is no doubt, as I have mentioned earlier in my paper, that the younger the children are brought for treatment the more easily is the disease eradicated and the W.R. converted from positive to a permanent negative.

Other authorities say that every case of congenital syphilis should be treated for at least two years, and Colonel Burke goes even further, I believe, and treats them for five years. From my own experience I should say that this is a counsel of perfection in a large majority of cases, and one which at any rate in London we should find it extremely difficult to adopt as a routine practice.

When we come to ask what are the criteria of cure, I suppose the complete cessation of any symptoms of activity, we should all agree, is absolutely essential, and I think also we should agree that the blood and c.s.f. on testing should be quite normal. Can we fix any limit for the time this satisfactory state of things has persisted, after which we can regard the patient as cured ? I have not yet succeeded in fixing upon a limit, because, as I have already mentioned to you, I have had a case which relapsed with I.K. after having had a negative W.R. for eight years.

This leads up to the next point, namely the question of Wassermann fastness. Do we know what brings about this condition, except that it is commoner in the children who come under observation late than in those who are brought to us in infancy? In fact, I have never 


\section{TREATMENT OF CONGENITAL SYPHILIS}

seen a case of Wassermann fastness in an infant, or in a child whom I had started to treat in infancy. I have a number of older children whose Wassermann I cannot make negative even in spite of fifty or more injections of arsenic and mercury by mouth. I believe Wassermann fastness is more likely to occur in cases in which the c.s.f. is positive, and that treatment with malaria is useful in these cases. I have occasionally found that a strongly positive blood W.R., which I have been unable to make negative by means of treatment, had become negative when the patient was examined again years afterwards. If the W.R. should relapse after having become negative, even though there were no symptoms of active disease, most of us here would agree that further treatment should be given.

The last three points in the series of questions may not detain us very long, although they formed a subject of discussion at the Congress at Geneva in I932. Should children who are discovered to have a positive W.R. and no other signs of syphilis be treated ? I personally would treat such patients. Secondly, should the apparently healthy children of syphilitic parents be treated if the W.R. is negative? A number of continental authorities answer this question in the affirmative, and possibly some of you may agree with them. I personally would not treat such children if I could make certain that they would be kept under prolonged observation and examination, say once a year until puberty. If not, it might be desirable to give them some treatment. Finally, should one treat the apparently healthy child of a mother who has been treated during pregnancy ? Here again, I would say " No," but would keep the child under observation as long as possible.

Ladies and Gentlemen,-I have now come to the end of my remarks, and I have intentionally refrained from going into any considerable detail as to the treatment of congenital syphilis as carried out at the clinic at Great Ormond Street, because I believe a more useful purpose will be served by hearing the views and experiences of as many of you as possible. My remarks are intended to provoke discussion, from which I hope we shall be able to draw certain conclusions, and perhaps make certain generalisations which will be of help to ourselves and of value to the community. 


\section{BRITISH JOURNAL OF VENEREAL DISEASES}

In order to serve as a guide to members, and to crystallise the discussion, the following series of questions was drawn up :-

A. (I) Do you rely solely on mercury?

(a) by mouth, (b) by inunction, (c) by injection; if $(a),(b)$ or $(c)$, which preparation ? $(d)$ by any - other mode of administration, $(e)$ by combinations of the foregoing.

(2) If so

(a) is it used for older children, as well as infants ?

(b) is it to be preferred for any particular type of case, e.g., infantile, osseous or nerve syphilis, interstitial keratitis, etc. ?

(c) is it used continuously or with periodic intervals ? If the latter, are any other drugs given in the interval?

B. (I) Do you rely on arsenicals ?

(a) by mouth; drug, dosage and duration of courses?

(b) by injection; which preparation?

(i.) in infancy.

(ii.) in older children, and are any particular drugs used in special types of case?

(2) Details of injections :-

(a) intramuscular or intravenous.

(b) dosage at different ages-with the maximal doses given.

(c) length of each course ; whether six, eight, ten or twelve injections in a course?

(d) are there any intervals between courses, and, if so, are other drugs given then?

(3) Are any other drugs given with the arsenicals ?

(a) mercury, (i.) by mouth, (ii.) by inunction, (iii.) by injection?

(b) bismuth, which preparation?

(c) any other drug?

Concurrently with the arsenic, or alternately?

C. Do you rely on bismuth alone ?

(I) If so, which preparation do you use ?

(2) Do you prefer bismuth for any particular tyre of case? 


\section{TREATMENT OF CONGENITAL SYPHILIS}

D. Iodides : do you give these? If so, in what type of case, and when ?

E. Adjuvants.

F. Neuro-syphilis :

What is your experience in this form of congenital syphilis?

Early and late neuro-syphilis. Best form of treatment ?

Prognosis?

G. Interstitial keratitis.

(I) Treatment during first attack ?

(2) Treatment during relapses ?

(3) Are relapses prone to occur after one form of treatment rather than any other ?

H. Toxic effects of drugs, their prevention and treatment.

I. Duration of treatment and criteria of cure.

J. Wassermann fastness. Are there any known factors?

(I) Does it occur in infants?

(2) Does it occur after one form of treatment rather than another?

(3) Can it be obviated ? or

(4) Cured? Does malaria cure it, either alone or followed by other injections?

(5) Relation to positive c.s.fl. ?

K. W.R. relapses. Should they be treated? If so, how?

L. Should children with positive W.R. only be treated ?

M. Should "healthy" children of syphilitic parents be treated if W.R. is negative?

$\mathrm{N}$. Should one treat the apparently healthy child of a mother who has been treated during pregnancy? 